
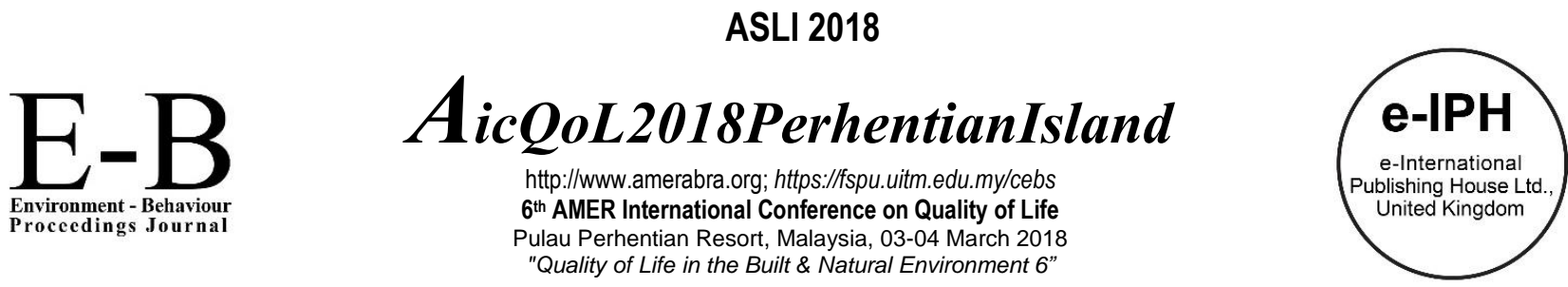

\title{
A Review of Sensory Design Physical Learning Environment for Autism Centre in Malaysia
}

\author{
Roslinda Ghazali ${ }^{1}$ Siti Rasidah Md Sakip, Ismail Samsuddin \\ ${ }^{1}$ Department of Post-Graduate, \\ Universiti Teknologi MARA, Bandar Baru Seri Iskandar, Perak. \\ lindakeruing@gmail.com, sitir704@perak.uitm.edu.my, ismai587@perak.uitm.edu.my \\ Tel: +6013-5185148
}

\begin{abstract}
Autism Spectrum Disorder (ASD) is a neurodevelopmental disorder that impairs verbal and non-verbal communication and social interaction by showing themselves in repetitive behaviour, sensory issues, and cognitive delay. With proper learning environment, autistic children can continue their lives with their peers who exhibit regular development. The paper aims to develop a conceptual sensory design of Autism Physical Learning Environment. The objective is to identify sensory issues for design consideration in a physical learning environment. Perhaps, this could help designers to gain better understand the variables of certain school design features and school facilities.
\end{abstract}

Keywords: Sensory design; autism; physical learning environment;

eISSN: 2398-4287@ 2018. The Authors. Published for AMER ABRA CE-Bs by e-International Publishing House, Ltd., UK. This is an open access article under the CC BYNC-ND license (http://creativecommons.org/licenses/by-nc-nd/4.0). Peer-review under responsibility of AMER (Association of Malaysian Environment-Behaviour Researchers), ABRA (Association of Behavioural Researchers on Asians) and cE-Bs (Centre for Environment-Behaviour Studies), Faculty of Architecture, Planning \& Surveying, Universiti Teknologi MARA, Malaysia.

DOI: https://doi.org/10.21834/e-bpj.v3i7.1262

\subsection{Introduction}

The Malaysian Government aims to become a regional center for education and targeted to have as many pupils as possible attend the pre-school education. Although pre-school is not part of formal education, it is important for children at the age four to six years old to attend as preparation for the next primary education which lasts 6 years and is intended for pupils aged seven to twelve years old. Children develop skill, social interaction and develop their fullest potential while in preschool. A quality and properly designed physical learning environment will enrich the development and education of children. Ensuring the quality of preschool contributing to improving school readiness among children and a better education system (Shaari \& Ahmad, 2016). However, children with disable also are not exclude from education. Disable children to Malaysia's Person with Disabilities (PWD) Act stated that those who have long-term physical, mental, intellectual or sensory impairments which in interaction with various barriers may hinder their full and effective participation in society. Children with disable categories under learning difficulties. They are included in the condition that affects the learning ability of an individual such as Autism Spectrum Disorder (ASD), Attention Deficit Hyperactivity (ADHD) and specific learning difficulties such as (dyslexia, dyscalculia, and dysgraphia (UNICEF, 2014).

Autism Spectrum Disorders (ASD) has occurred in every nation of the world. It gives impact providing life-long care to their affected relative. Limited resources and research on developmental disabilities focus on children with ASD and the effects on parents of having a child with ASD has been limited largely to families in western countries. Nearly all prevalence studies reviewed undertaken in Western countries or Asian affluent countries such as Japan (Samadi \& McConkey, 2011). Their research has limited information on the identification of children with this condition in non-Western, less affluent countries where services for children with any form of special needs are less developed. This shortage of information has raised the unwarranted assumption made by some writers, that autism is

eISSN: 2398-4287@ 2018. The Authors. Published for AMER ABRA cE-Bs by e-International Publishing House, Ltd., UK. This is an open access article under the CC BYNC-ND license (http://creativecommons.org/licenses/by-nc-nd/4.0/). Peer-review under responsibility of AMER (Association of Malaysian Environment-Behaviour Researchers), ABRA (Association of Behavioural Researchers on Asians) and cE-Bs (Centre for Environment-Behaviour Studies), Faculty of Architecture, Planning \& Surveying, Universiti Teknologi MARA, Malaysia.

DOI: https://doi.org/10.21834/e-bpj.v3i7.1262 
rare in non-Western cultures. While in Malaysia, the Ministry of Health reported that 1 out of 600 children in Malaysia is autistic in 2004. However, the prevalence rate is closer to the rates in developed countries such as 1 in 68 in the US and 1 in 100 in the UK (Chiam, 2016). The increasing trend reflects a global rise in the prevalence of autism such as in the US, there has been a tenfold increase in autism cases in the last 40 years. While in Malaysia, the number of individuals with autism has been increasing at $3 \%$ per year (Mansor, 2016; Chiam, 2016; Metro, 2017). With the tremendous in numbers, it gives impact to the country, community, education, and family. Chiam reported that NGOs, private learning centers, and healthcare professionals have been recommended by to government the overcome the cases to equipped in treating and care for autistic individuals.

The problem with autistic children is having difficulty impairments in social, communication, and behavioral skills. However, an autistic child can survive independently with encouragement to continue their education in different learning environments. Without the appropriate educational arrangements, autism becomes a lifelong handicap that affects the lives of the individuals and the people around them. With proper learning environment, many autistic children can continue their lives with their peers who exhibit regular development (Cikili et al., 2015). Knowing them as a unique person, designated learning environment should consider the sensory issues to overcome their needs. However, designers are lack of experience in terms of sensory design while designing learning spaces for autistic children (Mcnally, Morris, \& Mcallister, 2013). Architects role and responsibility is to provide a design that responds to the needs of all members of society. However, designers are lack of awareness of sensory issues regarding the built environment in the daily life of autism before designing stage. Any unwanted distraction can influence negatively upon that child's ability to learn (Mcnally et al., 2013). Once autistic children starting their learning process, the quality of the environment is so much important and avoid confusing and frustrating to the autistic mind (Beaver, 2011).

They suggested that autistic children are encouraged to continue their education in different learning environments. A designated learning environment for autistic children is unique. Chiam also mentioned that ASD is a cluster of neurodevelopmental disorders that impairs verbal and non-verbal communication and social interaction by showing themselves in repetitive behaviour, sensory issues, and cognitive delays. Therefore, designing learning environment should consider the sensory issues to overcome a critical set of human factors when designing built environments-the effects of sensory stimulation on people who use the environment (Paron-Wildes, 2005). They can survive independently with encouragement to continue their education in different learning environments. However, how far the status quality of Autism Physical Learning Environment? The paper aims to develop a conceptual sensory design of Autism Physical Learning Environment. The objective is to identify sensory issues for design consideration in a physical learning environment.

\subsection{Literature Review}

\subsection{What is Autism?}

The definition and description of autism have tremendously changed from time to time since the 1800s. The first Diagnostic Statistical Manual (DSM) in the year 1952 identified autism as a childhood subtype of schizophrenia by American Psychiatric Association (Cook \& Willmerdinger, 2015). They discovered that French physician named Jean-Marc Gaspard Itard described autism as "Victor the Wild Boy of Aveyron". The story began in 1798 when Itard found a young boy isolated for 11 years from his society because of his language and intellectual disabilities. Itard described Victor as being developmentally different from other children at his age and later was formally characterized as autistic. Autism is becoming more prevalent, and the diagnostic spectrum criteria evolved by the time the DSM-5 has published in 2013 and definition are likely to continue to change in the future.

Autism Spectrum Disorder (ASD) is a neurological disorder that affects a child's developmental disability causing social, communication and behavioral challenges (Yates, 2016). An individual with autism often affects a child's ability to communicate, understand language, play and relate to others (Boyce, Hunter and Howlet, 2013). They also identified that the symptoms as such repetitive activities, stereotyped movements, struggle to adapt to the environment and the daily routine and unusual responses to sensory experiences. Autism spectrum disorders (ASD) is characterized by social communication and social interaction (Yeo and Teng, 2015). The researcher mentioned that ASD restricted repetitive patterns of behavior, interests, and activities. Not only that ASD having poor in social especially poor eye contact, lack of joint attention, pedantic or odd speech patterns, lack of social problem-solving ability, lack of empathy, and difficulties interpreting body language. Children with ASD are having difficulties in developing their language skills, hearing and communicating. Therefore, they express themselves with exhibit unconventional behaviors such as being aggressive, bad temper or injuring themselves.

\subsection{Physical Learning Environment}

The learning environment refers to the space allocated for classrooms, science labs, open spaces and offices (Amirul, Che Ahmad, Yahya, Lee Abdullah, Adnan and Mohamed Noh, 2013). They defined learning environment as the social context, psychological and pedagogical, which can affect learning, achievement, and attitudes of the students. Learning environment and features that are in it played a major role in improving learning in schools and is identified as major determinants of student learning. Learning environment capable of stimulating students to engage in the learning process and be able to influence the behavior of students as well as to assist in the development of their skills or cognitive perception.

According to Fraser (1994) and Kilgour (2006), two major components of the learning environment were identified - physical component and psychosocial component. The physical component includes all physical aspects such as classrooms, teaching materials and learning facilities, both inside and outside the classroom. Psychosocial component related to the interaction that occurs between students and students, students with teachers and students with the environment. Both of these components complement each other in 
creating and shaping the learning environment and affect the learning processes that occur in it showed in figure 1. Since researcher based on architecture, the interest would focus only the physical aspects such as school building and classrooms both inside and outside the classroom.

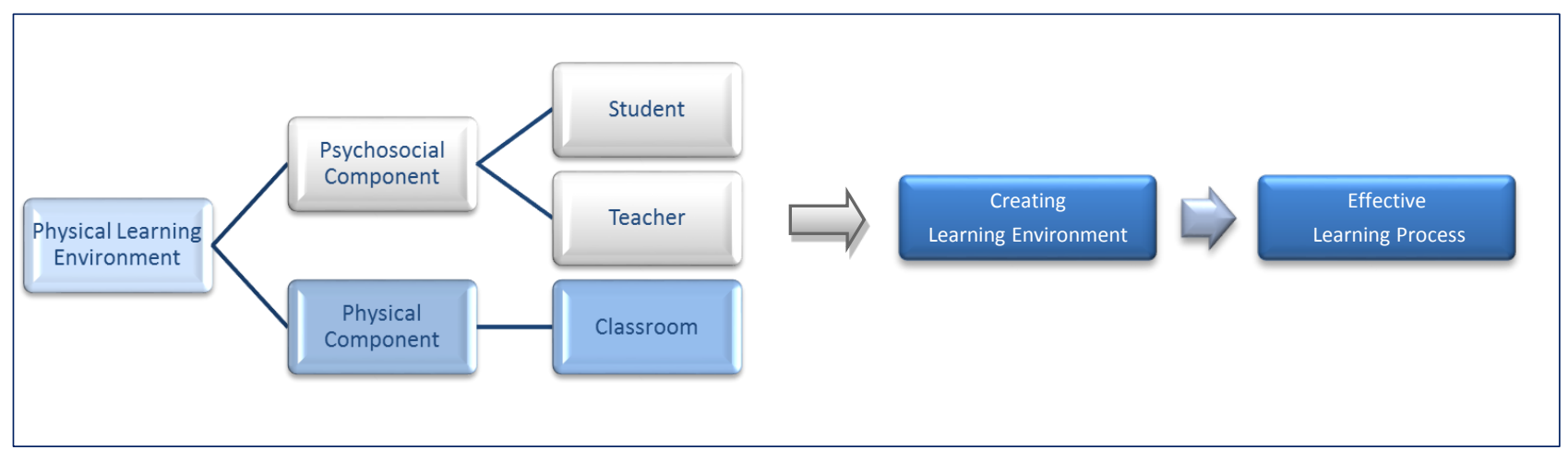

Fig. 1: The Physical Learning Environment Framework

\subsection{Sensory Design}

The environment gives a huge impact on a child with Sensory Sensitivity; also known as Sensory Processing Disorder or Sensory Integration Difficulty. Their senses can be either over-developed (hypersensitive) or under-developed (hyposensitive) which can result in feelings of anxiety, stress \& occasionally, physical pain. Both can have an impact on how a child handles different environments (Barker, 2014). The sensory design is design for living which how space feels, sounds, looks, smells, and functions can be incredibly affecting one or more of the seven senses which can have an overwhelming effect on their life (Society, 2015). The sensory quality framework shows in figure 2 to explain the relation of both situations that beneficial to autism learning environment.

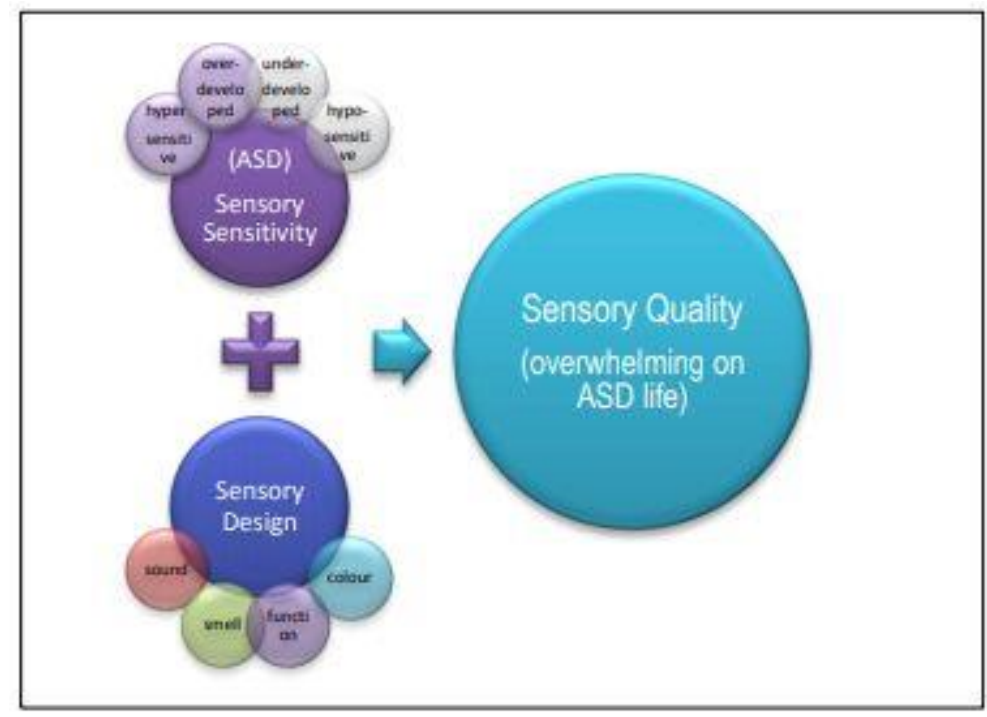

Fig. 2: The Sensory Quality Framework

Research done by Paron-Wildes (2005) explained that when designing children's environments, it is important to consider the needs of children with neurological disorders and to think through space as an experience. He explored with individuals suffering from problems with sensory integration or sensory defensiveness and revealed that autistic does not typically fall within the "normal" or "average" range of sensory values that are experienced. Therefore, an architect should consider designing spaces according to their sensory quality. This means grouping spaces into 'high-stimulus' and 'low-stimulus' areas with transition zones aiding the shift from one zone to the next (Society, 2015). It also mentioned that design spaces in a logical order based on the use to support routine and predictability. The use one-way circulation helped people moving between activities as seamlessly as possible with minimal distraction is important to autism. Escape place is to provide space for relief from the overstimulation of the environment. Space might be a small, partitioned area or crawl space in a quiet section of a room or building with the sensory environment neutral and customizable (Society, 2015). The theoretical framework of sensory design in figure 3 shows the worldwide paradigm and the following research as a whole. 


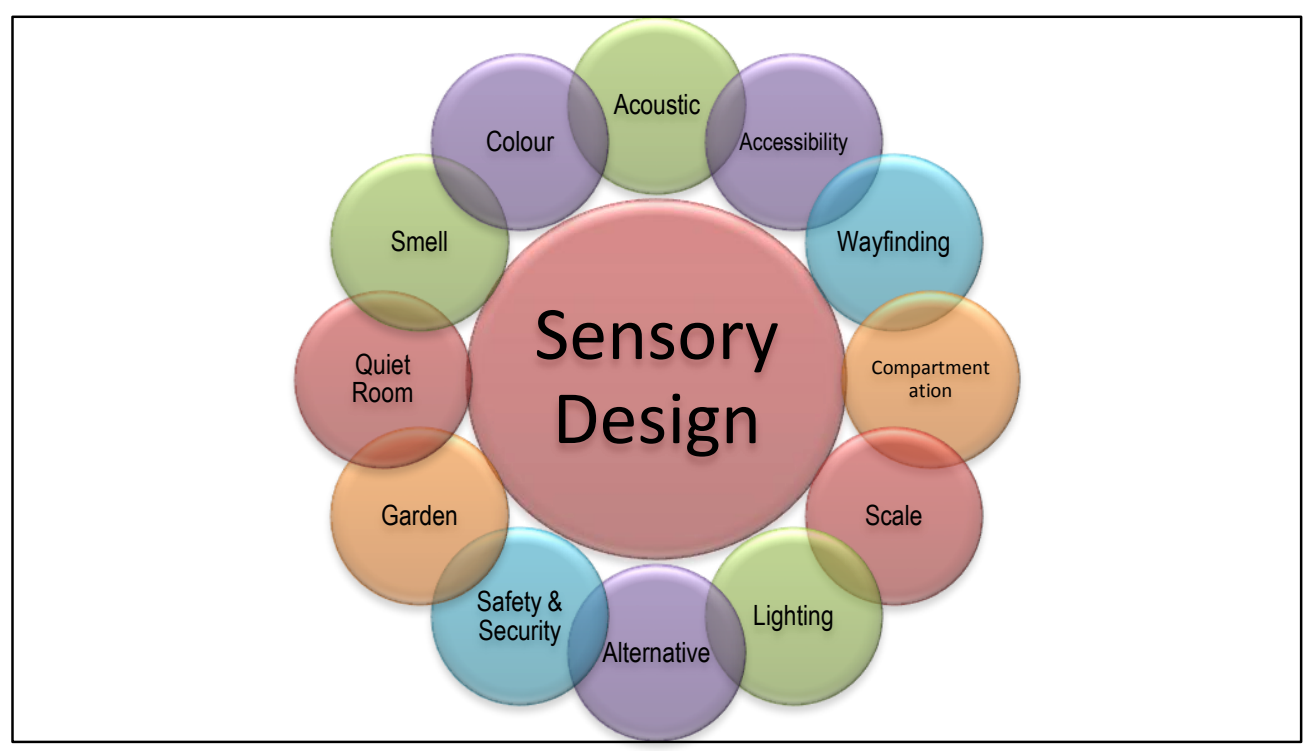

Fig. 3: The Theoretical Framework of Sensory Design

\subsubsection{Acoustic}

Acoustics is one of the most important issues in the interior design requirements for autistic children. Children with autism are afraid of noise and need a quiet environment for their comfort. The repetitive behaviour usually exhibits dealing with this problem due to their chronically high level of stimulation. If the classrooms and learning environments are not designed to accommodate the autistic children, it assumes that they will not learn these important skills and may struggle to live in our society. Therefore, the designer should consider a strong correlation between the level of noise and inappropriate behaviors of children with autism. Research has shown that their attention lengths, response times and behavioral temperament improved by reducing noise levels and echo in a learning environment for children with autism. Therefore, the building must be accommodated with proper mechanism \& soundproofing (Mostafa, 2014; Nazri \& Ismail, 2016; Altenmüller-Lewis, 2017). Research Institude (2014) revealed that excess noise could be at best distracting and at worst with sensory overload. They suggested that designers should aware to reduce sounds, rattles, and related noises from ventilation and related systems. Not only sound from internal sources but also the external environment such as traffic also important to consider in the design phase. While choosing the right material for the acoustic ceiling to reduce noise, as well as carpet, which will help absorb sound.

\subsubsection{Colour}

The colours play important role and may affect autistic behavior. Architect or designer should avoid disturbing and overly stimulating colours. Researchers suggested careful choices of colours to ensure a good balance between the shared and private spaces. Neutral, calming colours and the use of natural materials are best suited for autism-friendly learning environments (Altenmüller-Lewis, 2017; Nazri \& Ismail, 2016). Autistic children having difficulties in the classrooms that have too much stimulus on the walls, doors, and desks. They become confused and difficult to pay attention to many things occupying their sight. Therefore, the learning environment is essential with a modification made to simplify the environment with soothing and natural colour to reduce the number of stimuli (Sachs \& Vicenta, 2011).

\subsubsection{Smell}

Autistic children having difficulties and problematic with strong smells and even odours. Mcnally et al. (2013) addressed that school kitchens, dining halls, swimming pools and bin areas are all potentially problematic sources of strong smells. However, Jacobson (2015) reported that children with autism might not inhale sweet and foul scents through their noses like the way other children do. As mentioned by Jacobson, most people inhale deeply when the smell is pleasant but sniff more tentatively when it is not. For normal children, they will hold in the controls, but an autistic child did not seem to react to the quality of the odor: They sniffed with more or less the same intensity for each type.

\subsubsection{Lighting}

Natural and artificial lighting need to compose throughout educational facilities. The lighting levels can create active and calm zones throughout the schools and should design appropriately to suit their activities. The designer should carefully control of reflections, glare and shadow patterns of interior spaces. While artificial lighting should be equipped with dimming controls to allow for adjustments or designed as an indirect light source to create a glowing interior. Autistic children are sensitive to light where they will avoid a flickering light, once we switch on the pendaflour light (Nazri \& Ismail, 2016; Altenmüller-Lewis, 2017). Ideally, supported by Research Institude (2014) lighting should be dimmable as possible to comfort autistic children with sensory sensitivities. The best solution recommended by designing the pelmet lighting where the light source is not visible. Allocation of windows at both low and high level in the classroom 
can also be beneficial. Viewing through the windows to the outside can implement at eye level while still admitting natural light to the classroom. However, it is important to avoid solar gain and glare from direct sunlight that can be an issue for children with ASD. If windows are present, designers should consider utilizing windows with shades placed between the glasses rather than traditional vinyl shades. (Mcnally et al., 2013; Research Institude, 2014)

\subsubsection{Accessiblilitiy}

Arrival at the school is an extremely important moment for all children. Children with autism, having difficulties to deal with, when they change the environment from the comfort of home moving to the hustle and bustle of the school environment can be distressing. The architect who designs the school environment should make this transition as straightforward and as stress- free as possible. This will help to make the experience tolerable and hopefully even enjoyable for the autistic child (Mcnally et al., 2013).

\subsubsection{Wayfinding}

Circulation areas can be potentially distressing for pupils. Becoming disorientated or lost can cause great stress to a child with ASD. Complex layouts, long corridors and frequent changes of level can contribute to a feeling of disorientation and create a sense of anxiety. It is important that effort is made to ensure that circulation around the school is as clear and comprehensible as possible. These factors should consider during the design stage of a building. Difficulties experienced by individual pupils with ASD should also observed in-situ with a view to the implementation of suitable mitigating measures (Mcnally et al., 2013).

\subsubsection{Compartmentation}

Compartmentation is to organise a space or building into compartments with clear functions and sensory qualities that help define the user. Separate spaces using furniture, floor covering, floor level or lighting to organize the space. Using transition zones helps the individual recalibrate their senses as they move from one level of stimulus to the next. These spaces may be anything from a distinct node that indicates a shift, to a full sensory room (Society, 2015).

\subsubsection{Building Scale}

Children with ASD will be most calm in an environment that they can easily comprehend. Small-scale schools or those with simple building layouts offer the most basic surroundings for easy comprehension. The scale of a large school can be daunting for a pupil with ASD. The sheer number of buildings, doors, windows, staircases and the variety of classrooms, corridors, offices and countless other rooms that go to make up the landscape of any large school can present a stimulating yet sometimes disorienting universe for most children (Mcnally et al., 2013).

\subsubsection{Quiet Room}

Children with ASD can begin to demonstration disrupting behaviour when they become tired, distressed or overstimulated. It needed to allow the children to calm down and in effect 'recharge their batteries.' A quiet room will be an area acoustically separated from but directly accessed from the classroom. It may also treat as a flexible space, sensory room or as a small reading area that can contribute to the learning environment. A quiet room designated within the classroom itself or alternatively, it may be separate from but adjacent to the classroom. Empirical research has shown a neutral sensory environment gives a positive effect of such spaces with minimal stimulation, particularly in learning environments. Such spaces may include a small partitioned area or crawl space in a quiet section of a room, or throughout a building in the form of quiet corners (Mcnally et al., 2013; Mostafa, 2014).

\subsubsection{Safety and Security}

An architect and designer should aware of the need to design the so-called 'architectural barriers'. Arnaiz, Segado, \& Albaladejo (2011) mentioned that behavioural problems related to cases of ASD and they would be aggressive at any time. Therefore, they suggested that elements in the built environment should be designed and bearing in mind the possibility of eventual abuses. They also mentioned that bathroom equipment, lighting fixtures and mechanisms, hardware, banisters, wall and floor tiles must well anchor. Autistic children have the tendency to escape and run away. Therefore, mechanisms and warning systems that make unobserved leaving of spaces or facilities difficult to exit unseen need to be developed. The layout design and setting of the facilities should allow the possible freedom for all users while minimizing hazards, security risks or behavioural triggers for those with ASD (Altenmüller-Lewis, 2017). Safety and security is the most importance and concern when designing learning environments. Vulnerable children may have difficulty realizing the dangers inherent in their environment and may have an altered sense of their environment. Designers should aware the fittings to protect from hot water and an avoidance of sharp edges and corners (Mcnally et al., 2013; Mostafa, 2014).

\subsubsection{Garden}

Autistic children responded positively in the garden. Exercise in a natural environment may promote directed attention and social interactions among autistic, which may positively influence exercise intentions (Hansen, Blakely, Dolata, Raulston, \& Machalicek (2014); Rogerson, Gladwell, Gallagher \& Barton (2016)). While research done by Hussein (2011) explored how autistic child utilized the garden. She revealed the highest number of users, use of sensory gardens by observing the zones and she discovered the pathways that link the sensory garden to the site context which continuous pathways with easy access to the features. Autistic children spent a long time in zones where sensory provided rather than aesthetic values emphasized. Rachel and Stephen Kaplan (1989) have linked contact with nature to restored attention, recovery from mental fatigue, and enhanced mental focus. Studies (Faber Taylor, Kuo, and Sullivan, 2001; 
Kuo \& Faber Taylor, 2004) by researchers at the University of Illinois concluded that children with attention deficit disorder (ADD) show a greater ability to focus immediately after spending time in nature. The conclusion by these researchers is that that the greener a child's everyday environment the more manageable their ADD symptoms. Creating outdoor play and connecting children with nature would give them an opportunity to have fun and provide some relief from a rigid classroom. Designing outdoor spaces is necessary for the designer to develop play spaces with accessibility, nature-based, fun places for all children to enjoy. This could ultimately help children in their learning process even though their different abilities, they have more in common with each other (Sachs and Vincenta, 2011).

\subsubsection{Alternative}

The art therapy area incorporates various activities such as painting; printing, sculpture, and pottery give benefits to an autistic child. Activities located outside the classroom with natural lighting creates an enjoyable and creative environment. Pre-vocational and artwork workshop can be integrated to help students create beautiful and functional objects such as simple furniture, leather goods and home accessories (Mostafa, 2014). Pet therapy also as an alternative therapy for autistic through increased social interaction and communication as well as reduced problem behaviors, autistic severity, and stress (O'Haire, 2013).

\subsection{Conclusion}

Researcher considers having to visit similar learning environment for autism and observe the sensory responses to the environment. Children with neurological disorders possibility having impairment insight, hear, smell, and feel. It is important for the designer to experience the environment before designing autistic children's environments. Perhaps this research could contribute to architects and designers to use during the design stage and create a quality environment for autistic children within the Malaysian context. Therefore, future research needed to explore the effects of physical learning environment on the performance of children with autism. The researcher could elaborate by studying the effect of every impact of twelve parameters in improving performance. Hence, by further strengthened the environmental interventions it is hoped that the study would help the designer creating conducive learning environment not only optimises the classroom environment but upon parent's and interventionist's satisfaction.

\section{Acknowledgements}

I would like to thank my supervisor Dr. Siti Rasidah Md Sakip and Asso. Prof. Dr. Ismail Samsuddin for supporting me. In addition, I would thank Jabatan Kerja Raya Malaysia for giving me the opportunity to further my study.

\section{References}

Altenmüller-Lewis, U. (2017). Designing Schools for Students on the Spectrum. The Design Journal, 20(sup1), S2215-S2229. https://doi.org/10.1080/14606925.2017.1352738

Amirul, N. J., Nidzam, C., Ahmad, C., Yahya, A., Faizal, M., Abdullah, N. L., Noh, N. M. (2013). The physical classroom learning environment, (2nd International Higher Education Teaching and Learning Conference 2013), 9 pages

Arnaiz, P., Segado, F., \& Albaladejo, L. (2011). Autism and the Built Environment. Autism Spectrum Disorders - From Genes to Environment, 363-380. https://doi.org/10.5772/20200

Barker, K. (2014). Sensory Design For Autism. Retrieved December 18, 2017, from http://justlivinginteriors.co.uk/sensory-design-autism/

Beaver, C. (2011). Designing Environments for Children \& Adults with ASD. Ga Architects.

Boyce, P., Hunter, C., \& Howlett, O. (2003). The Benefits of Daylight through Windows. Lighting Research Center, 1(1), 1-88. https://doi.org/12180-3352

Chiam, M. (2016, April 18). Stepping Up. The Star. Malaysia.

Cikili, Y., Sari, H., \& Deniz, S. (2015). The Evaluation of the Qualifications of Teachers Working with Students with Autism in Turkey in Terms of Views of Teachers and Parents. In ICBTS (Ed.), The 2015 International Academic Research Conference (pp. 118-208). UK: University of London.

Cook, K. A., \& Willmerdinger, A. N. (2015). The History of Autism. The Furman University Scholar Exchange (Book 1). Furman University.

Hamzah, Z. (2016). 12,785 Golongan Autisme Berdaftar Dengan JKM. Utusan Malaysia. Malaysia. Retrieved from http://www.utusan.com.my/berita/wilayah/12-785 golongan-autisme-berdaftar-dengan-jkm-1.219119\#ixzz51T8GDinq, (retrieved 12 January 2018)

Hansen, S. G., Blakely, A. W., Dolata, J. K., Raulston, T., \& Machalicek, W. (2014). Children with Autism in the Inclusive Preschool Classroom: A Systematic Review of Single-Subject Design Interventions on Social Communication Skills. Review Journal of Autism and Developmental Disorders, 1(3), $192-206$. https://doi.org/10.1007/s40489-014-0020-y

Hussein, H. (2011). The Influence of Sensory Gardens on the Behaviour of Children with Special Educational Needs. Asian Journal of Environment-Behaviour Studies, 2(4), 343-354. https://doi.org/10.1016/j.sbspro.2012.03.356 
Luisier A-C, Petitpierre G, Ferdenzi C, Clerc Bérod A, Giboreau A, Rouby C \& Bensafi M (2015). Odor Perception in Children with Autism Spectrum Disorder and its Relationship to Food Neophobia. Frontier. Psychology. 6:1830. doi: 10.3389/fpsyg.2015.01830

Mansor, R. (2016). Majlis Pecah Tanah Program PERMATA Kurnia. Permata Kurnia. Malaysia. Retrieved from http://www.programpermata.my/en/patron/speeches/2013/majlis-pecah-tanah-program-permata-kurnia/

Mcnally, H., Morris, D., \& Mcallister, K. (2013). Experiencing Primary School through the lens of the autistic spectrum. Aldo goes to Primary School

Mostafa, M. (2014). Architecture for autism: Autism aspects in school design. Archnet-IJAR

Nazri, N. A., \& Ismail, Z. (2016). Educational building facilities for children with autism in Malaysia. Jurnal Teknologi. https://doi.org/10.11113/jt.v78.8489

O'Haire, M. E. (2013). Animal-assisted intervention for autism spectrum disorder: A systematic literature review. Journal of Autism and Developmental Disorders, 43(7), 1606-1622. https://doi.org/10.1007/s10803-012-1707-5

Paron-Wildes, A. J. (2005). Sensory Stimulation and Autistic Children. Implications, A Newsletter by InformeDesign, 6(4), 1-5.

Research Institude. (2014). Autism-Friendly Design Ideas. The Children's Hospital of Philadelphia. Centre for Autism Research, 1-2.

Rogerson, M., Gladwell, V. F., Gallagher, D. J., \& Barton, J. L. (2016). Influences of green outdoors versus indoors environmental settings on psychological and socia outcomes of controlled exercise. International Journal of Environmental Research and Public Health, 13(4). https://doi.org/10.3390/ijerph13040363

Sachs, N. \& Vincenta, T. (2011). Outdoor Environments for Children with Autism and Special Needs. Implications, A Newsletter by InformeDesign, 9(1), 1-8.

Samadi, S. A., \& McConkey, R. (2011). Autism in Developing Countries: Lessons from Iran. Autism Research and Treatment, 2011 (August), 1-11. https://doi.org/10.1155/2011/145359

Shaari, M. F., \& Ahmad, S. S. (2016). Physical Learning Environment: Impact on Children School Readiness in Malaysian Preschools. Procedia - Social and Behavioral Sciences, 222, 9-18. https://doi.org/10.1016/j.sbspro.2016.05.164

Society, T. N. A. (2015). Autism Friendly Design. Your Autism Magazine, 49(2), 513600-513600. Retrieved from http://www.autism.org.uk/professionals/others/architects/autism-friendly-design.aspx

UNICEF, M. (2014). Children with Disabilities in Malaysia. "Mapping the Policies, Programmes, Interventions, and Stakeholders." Convention on The Rights of The Child.

Zuljadan, M. A. (2017). Kempen Sokong Usaha Bantu Kanak-Kanak Autisme. Harian Metro. Malaysia. Retrieved from https://www.hmetro.com.my/node/224532 Retreived 12 January 2018 